\title{
Regional disparities in interferon therapy for chronic hepatitis $C$ in Japan: a nationwide retrospective cohort study
}

Naohiko Masaki ${ }^{*}$, Yoko Yamagiwa' ${ }^{1}$ Takuro Shimbo ${ }^{2}$, Kazumoto Murata $^{1}$, Masaaki Korenaga ${ }^{1}$, Tatsuya Kanto ${ }^{1}$, Masashi Mizokami ${ }^{1}$ and the prefectural members contributing to the Japanese Interferon Database

\begin{abstract}
Background: Many patients with chronic hepatitis C have been treated with interferon (IFN) therapy in Japan, especially after the introduction of subsidies for medical expenses in 2008. However, its performance and outcome have never been evaluated. Therefore, a nationwide, mail-based, retrospective cohort study was conducted.

Methods: Regional disparities in the demographic features, treatment performance, and virological response were evaluated using an intent-to-treat design. The participating prefectures were classified into nine regions from north to south (Hokkaido/Tohoku, Kanto, Shin-etsu, Hokuriku, Tokai, Kinki, Chugoku, Shikoku, and Kyushu). Multivariate logistic regression analysis was performed to select predictive factors for treatment performance and outcome.

Results: From December 2009 to May 2013, 16,854 patients with chronic hepatitis C were registered from 37 prefectures in Japan (median age: 60 years; $50.4 \%$ male; $74.8 \%$ IFN-naïve; HCV genotype [1 or 2]/viral load [high ( $\geq 5 \log \mathrm{IU} / \mathrm{mL}$ ) or low $(<5 \mathrm{log} \mathrm{IU} / \mathrm{mL})]: 1 / \mathrm{high}=58.2 \%, 1 / \mathrm{low}=5.2 \%, 2 / \mathrm{high}=27.3 \%, 2 / \mathrm{low}=7.5 \% ; 83.4 \%$ treated with peginterferon- $a$ and ribavirin). Mean age, proportion of elderly patients ( $\geq 65$ years), male sex, IFN-experienced, and HCV genotype were significantly different among the nine regions (all $P<0.001$ ). Regional disparities were independently selected as one of the predictive factors for treatment performance and outcome in patients treated with peginterferon-a and ribavirin, which revealed two regions that required further investigation.

Conclusions: Regional disparities still exist in IFN therapy, and are strongly associated with treatment performance and outcome. Since the accessibility to medical resources for individual patients seemed to be different among the nine regions, public health actions should be focused on how to construct and properly manage consultation networks between base hospitals and local clinics, especially in those regions with low population density.
\end{abstract}

Keywords: Treatment performance, Treatment outcome, Peginterferon-a, Ribavirin, Subsidy policy

\section{Background}

There are 130-150 million people infected with hepatitis $\mathrm{C}$ virus (HCV) worldwide, and 350,000-500,000 patients die of HCV-related liver diseases annually (e.g., liver cirrhosis or hepatocellular carcinoma) [1]. Standard treatment for chronic hepatitis $\mathrm{C}(\mathrm{CHC})$ has been peginterferon- $\alpha$ and ribavirin $(\mathrm{P} / \mathrm{R})$, and the sustained virological response (SVR) rate has remained at $50 \%$, in difficult-to-treat cases

\footnotetext{
* Correspondence: nmasaki0808@gmail.com

'The Research Center for Hepatitis and Immunology, National Center for Global Health and Medicine, 1-7-1 Kohnodai, Ichikawa, Chiba 272-8516, Japan

Full list of author information is available at the end of the article
}

of HCV genotype 1 and high viral load [2]. The introduction of protease inhibitors, such as boceprevir [3, 4], telaprevir $[5,6]$, or simeprevir $[7,8]$ could improve the SVR rate up to $75-85 \%$ in interferon (IFN)-naïve cases. Furthermore, the era of IFN-free treatment with oral-only directly acting antivirals (DAAs) has just become a reality with SVR rate $>90 \%$ [9-11].

Standardized performance and outcome of antiviral therapy are essential to eradicating $\mathrm{HCV}$, which could significantly decrease the risk of progression to liver diseases (e.g., liver cirrhosis and hepatocellular carcinoma). For this purpose, the Japanese government and 47 local governments started nationwide strategies from January

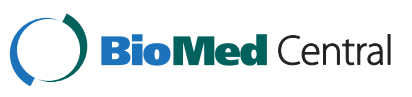


2007, to build intensive treatment networks in all prefectures, authorized later by the Basic Act on Hepatitis Measures (Act No. 97, December 4, 2009) [12]. Almost concurrently, subsidies for antiviral treatment (e.g., IFN therapy for patients infected with hepatitis B virus [HBV] or $\mathrm{HCV}$, or nucleoside analogs for those infected with HBV) were introduced to provide more patients with a higher chance of virological response. For example, the total medical expenses for 48 weeks of standard care for a patient with CHC could reach 23,930 USD for peginterferon- $\alpha 2 \mathrm{a}(180 \mu \mathrm{g}=278.3 \mathrm{USD})$ and ribavirin $(800 \mathrm{mg}=31.5 \mathrm{USD})$ combination therapy. The patient will have to pay 600 USD for P/R every month, as the average coverage of health insurance is $70 \%$ in Japan. With the aid of this subsidy policy, the patients will only have to pay 100-200 USD monthly according to their taxable income. More than 117,000 patients benefited from this subsidy policy during the initial 4 years (April 2008 to March 2012). The fact that the substantial amount of public money was allocated for the subsidy policy urged us to perform a nationwide retrospective study to evaluate whether the performance and outcome of IFN therapy have been standardized throughout Japan.

\section{Methods}

\section{The outlines of the study}

The Hepatitis Information Center of the National Center for Global Health and Medicine (Chiba, Japan) started a retrospective cohort study to construct the Japanese Interferon Database in December 2009. All 47 prefectural governments were invited to join this project. Currently, 37 prefectures have been participating and sending data to the Hepatitis Information Center. The standard duration of $\mathrm{P} / \mathrm{R}$ therapy was 48 weeks and 24 weeks for genotype 1 and non-genotype 1 , respectively, and the final therapeutic outcome was determined 24 weeks after the treatment period, according to the guidelines of the American Association for the Study of Liver Diseases [13] and the Japan Society of Hepatology [14]. The local governments had the application forms submitted by each patient, in which the genotype or serotype of $\mathrm{HCV}$, viral load, scheduled date of treatment, and demographic features of the patients were described. Therefore, the requests to draw up the reports on therapeutic outcomes were made in a timely manner to the relevant doctors by the local governments.

Most of the enrolled patients were treated by $P / R$ with weekly administration of peginterferon- $\alpha 2 a$ (Pegasys; Chugai Pharmaceutical, Tokyo, Japan) and daily ribavirin (Copegus; Chugai Pharmaceutical), or weekly peginterferon- $\alpha 2 b$ (Pegintron; MSD, Tokyo, Japan) and daily ribavirin (Rebetol; MSD). The dose of peginterferon$\alpha 2 \mathrm{a}$, regardless of the patient's body weight, was $180 \mu \mathrm{g}$.
However, the dose of peginterferon- $\alpha 2 b$ was adjusted based on the patient's body weight as follows: patients weighing $\leq 45 \mathrm{~kg},>45 \mathrm{~kg}$ and $\leq 60 \mathrm{~kg},>60 \mathrm{~kg}$ and $\leq 75 \mathrm{~kg}$, $>75 \mathrm{~kg}$ and $\leq 90 \mathrm{~kg}$, and $>90 \mathrm{~kg}$ were given $60 \mu \mathrm{g}, 80 \mu \mathrm{g}$, $100 \mu \mathrm{g}, 120 \mu \mathrm{g}$, and $150 \mu \mathrm{g}$ of peginterferon- $\alpha 2 \mathrm{~b}$ weekly, respectively. Patients weighing $\leq 60 \mathrm{~kg},>60 \mathrm{~kg}$ and $\leq 80 \mathrm{~kg}$, and $>80 \mathrm{~kg}$ were given $600 \mathrm{mg}, 800 \mathrm{mg}$, and $1000 \mathrm{mg}$ of ribavirin daily, respectively. Dose modification of peginterferon- $\alpha$ or ribavirin was based on the manufacturers' recommendations.

The format of the reports was unified and the demographic features of the patients included sex, date of birth, scheduled treatment period, previous history of IFN therapy, clinical and/or histological diagnosis, and IFN regimen. The data for virological markers, including viral load and serum transaminases levels, were collected before treatment, at cessation of treatment, and at final analysis. Peripheral platelet counts during the pre-treatment period were included. Determination of serotype and/or genotype (if possible) was a prerequisite for the standard treatment of chronic HCV infections in Japan. HCV RNA was determined by quantitative real-time polymerase chain reaction (COBAS AmpliPrep/COBAS TaqMan HCV Test; Roche Molecular Systems, Pleasanton, CA, USA). A high viral load was considered $\geq 5.0 \log 10 \mathrm{IU} / \mathrm{mL}$ HCV RNA. Together with these demographic features, information regarding virological outcome, treatment performance (i.e., accomplishment or withdrawal), reasons for treatment withdrawal (i.e., severe adverse events or other unrelated events), and personal information including patient identification and written informed consent were reported to the local governments. Thereafter, the data without personal information were sent to the Hepatitis Information Center with assigned temporary identifications to maintain anonymity in future references.

To analyze possible regional disparities in treatment performance and virological response, the 37 prefectures participating in this study were classified into nine regions from north to south as follows (numbers in parentheses denote the number of participating prefectures in each region): Hokkaido/Tohoku (6), Kanto (4), Shin-etsu (3), Hokuriku (3), Tokai (3), Kinki (6), Chugoku (4), Shikoku (3), Kyushu (5) (Fig. 1).

\section{Virological response}

Virological response was assessed by each doctor in charge according to the standard criteria described below. SVR was defined as undetectable HCV RNA levels in serum 24 weeks after cessation of treatment, while transient virological response (TVR) was defined as reappearance of HCV RNA in serum following undetectable HCV RNA at cessation of treatment. Nonvirological response (NVR) was defined as $<2$ log-unit decline in serum $\mathrm{HCV}$ RNA levels from the pre-treatment baseline value within 


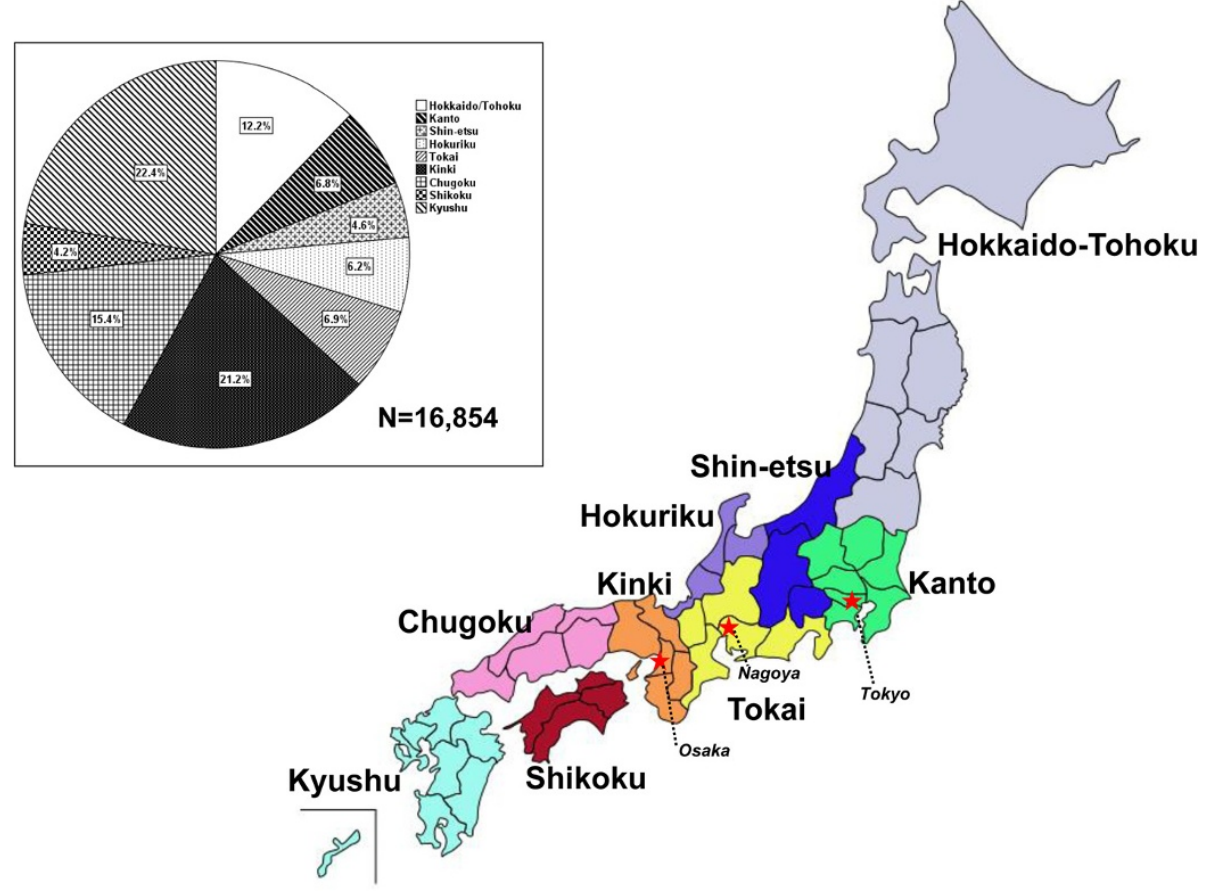

Fig. 1 A map showing nine regions of Japan. The percentages of $\mathrm{CHC}$ cases for each region are shown in the small inset. The three biggest cities, Tokyo, Osaka and Nagoya are located in Kanto, Kinki and Tokai, respectively

the first 12 weeks, or detectable viremia at 24 weeks after treatment initiation. Patients who were withdrawn from treatment because of the presence of serum HCV RNA at 24 weeks of therapy, or viral breakthrough, or who were lost during treatment or follow-up were included in the intent-to-treat analysis.

\section{Evaluation of liver fibrosis}

Since liver biopsy has not been regularly performed in recent clinical settings, a simple non-invasive index (Fibrosis-4 [FIB-4] index), which correlates well with hepatic fibrosis as determined by liver biopsy [15], was used to evaluate the extent of liver fibrosis. The FIB-4 index was used for multivariate logistic regression analysis, instead of clinical diagnoses.

\section{Ethics statement}

The study protocol complied with the Helsinki Declaration and was approved by the Ethics Committee of the National Center for Global Health and Medicine, Japan (\#738; October 1, 2009). Written informed consent was obtained from the patients prior to enrollment.

\section{Statistical analysis}

Continuous variables were expressed as median and interquartile ranges, unless otherwise specified, and compared using the Mann-Whitney $U$ test or Kruskal-Wallis analysis. Categorical variables were compared using Pearson's $x^{2}$ test or Fisher's exact test. The demographic features of the patients were compared among the nine regions using Kruskal-Wallis analysis or Pearson's $\chi^{2}$ test. Multivariate analysis was performed using a simultaneous, non-stepwise, logistic regression analysis, with all examined parameters, regardless of the univariate analysis results. All $P$-values were two-tailed, and $P<0.05$ was considered statistically significant. Data analyses were performed using IBM SPSS Statistics for Windows, Version 20.0 (IBM Corp., Armonk, NY, USA).

\section{Results}

\section{Patient demographics}

From December 2009 to May 2013, 17,169 reports were sent to the Hepatitis Information Center. The etiology of chronic liver diseases was HBV alone $(n=315), \mathrm{HCV}$ alone $(n=16,838)$, and co-infection with HBV and HCV $(n=16)$. Hence, $98.2 \%$ of the reports $(n=16,854)$ were $\mathrm{HCV}$ related and further analyses were confined to patients with $\mathrm{HCV}$ infection. The percentages of reports from each region are shown in the small inset of Fig. 1. The age distributions of this cohort at every decade were as follows: $<9$ years $(n=3) ; 10-19$ years $(n=24) ; 20-29$ years $(n=310)$; $30-39$ years $(n=831)$; $40-49$ years $(n=$ $2141)$; $50-59$ years $(n=4916)$; $60-69$ years $(n=6625)$; $70-79$ years $(n=1915)$; $>80$ years $(n=45)$; and unknown $(n=44)$. The median age was 60.0 years (interquartile range, $52.0-66.0$ years). Demographic features (i.e., mean 
age, proportion of elderly patients [ $\geq 65$ years], male sex, IFN treatment, and HCV genotype distribution) differed significantly among the nine regions $(P<0.001$; Table 1$)$.

\section{Treatment performance and outcome in patients treated by peginterferon- $a$ and ribavirin}

About $83.4 \%(n=14,061)$ of the patients were treated with $\mathrm{P} / \mathrm{R}$. Therefore, further analyses were restricted to this regimen to clarify the current treatment performance and outcome in Japan. The average percentage of treatment accomplishment in the P/R-treated cohort was $82.8 \%$. The percentage of treatment accomplishment was higher than the average in five regions (i.e., Kanto, Hokuriku, Tokai, Chugoku, and Kyushu) and lower than the average in the other four $(P=0.009)$ (Fig. 2). SVR, TVR, NVR, and undetermined response differed significantly among the nine regions (Fig. 3, $P<0.001$ ). Such regional disparities were more clearly demonstrated by stratification with the $\mathrm{HCV}$ genotypes and viral loads. As shown in Fig. 4, regional disparities regarding treatment performance were detected in the genotype 2 subgroup $(P=0.018$, with Bonferroni method), especially with high viral load $(P=0.036)$, but not in genotype 1 . However, regional disparities regarding treatment outcome were confirmed in the subgroups with high viral load, regardless of $\mathrm{HCV}$ genotypes.

\section{Predictive factors for treatment performance}

To determine the factors associated with treatment accomplishment with $\mathrm{P} / \mathrm{R}$, univariate analysis was performed (Table 2). Treatment accomplishment rate was significantly lower in the elderly group (77.2 vs. $85.1 \%$ [ $<65$ years]), IFN-experienced cases (81.7 vs. $83.1 \%$ [IFN naive]), genotype 1 group (79.0 vs. $91.1 \%$ [genotype $2+3$ ]), and high viral load group (82.7 vs. $85.3 \%$ [low viral load]). Higher levels of serum aspartate aminotransferase (AST), FIB-4 index, and lower platelet counts were significantly associated with treatment withdrawal. In addition, treatment accomplishment rate gradually decreased in patients whose treatment was initiated in 2009 and later (i.e., $85.2 \%$ [-2008], $82.8 \%$ [2009], $80.2 \%$ [2010-]; $P<0.001)$.

We found that treatment accomplishment rate differed among the nine regions in the entire $\mathrm{P} / \mathrm{R}$-treated cohort $(P=0.009$, Fig. 2$)$, especially in the genotype 2 subgroup with high viral load (Fig. 4, upper panel), and was closely associated with treatment outcome (i.e., 95.8, 84.8 and $45.8 \%$ in SVR, TVR and NVR, respectively). According to the multivariate and simultaneous logistic regression analysis (Table 2), the following six factors independently contributed to treatment withdrawal: old age, genotype 1, high serum AST levels, high FIB-4 index, later year of starting treatment, and region. Treatment accomplishment rate was lower in Hokkaido/Tohoku and Shikoku, and higher in Tokai among 9 regions.

\section{Predictive factors for treatment outcome}

To evaluate factors associated with SVR in P/R therapy, univariate analysis was performed (Table 3). The SVR rates were lower in female patients (54.8 vs. $63.6 \%$ [male patients]), elderly patients (47.3 vs. $64.1 \%$ [ $<65$ years]), IFN-experienced cases (49.7 vs. $62.4 \%$ [IFN-naive]), genotype 1 group (48.9 vs. $80.8 \%$ [genotype $2+3$ ]), and high viral load group (57.7 vs. $80.2 \%$ [low viral load]). Serum AST and alanine aminotransferase (ALT) levels, peripheral platelet counts, and FIB-4 index were significantly different between SVR and non-SVR. In addition, SVR rates were increased in patients who had initiated treatment in 2009 and later (i.e., $56.8 \%$ [-2008], $59.0 \%$ [2009], and $60.6 \%$ [2010-]; $P=0.019$ ).

We were able to demonstrate that the treatment outcome was significantly different among the nine regions in the entire $\mathrm{P} / \mathrm{R}$-treated cohort $(P<0.001)$ and in the subgroups with high viral load, regardless of HCV genotypes (Fig. 4, lower panel). Furthermore, SVR rates were closely associated with treatment performance (i.e., 67.7 and $15.5 \%$ in treatment accomplishment and withdrawal, respectively; data not shown). According to the multivariate and simultaneous logistic regression analysis (Table 3), most of the factors independently contributed to non-SVR (i.e., female sex, old age, experienced IFN treatment, genotype 1, high viral load, low serum ALT levels, low peripheral platelet counts, high FIB-4 index, and region). SVR rates in patients who had initiated treatment in 2010 and later were higher during the periods examined. In addition, SVR rates were significantly lower in Hokkaido/Tohoku and Shikoku among 9 regions.

\section{Discussion}

In this study, regional disparities in the demographic features of IFN-treated patients (i.e., age, sex, history of IFN treatment, and prevalence of HCV genotypes) in Japan have been demonstrated for the first time. Furthermore, regional disparities in treatment accomplishment and outcome of standard treatment with $P / R$ were also observed. Regional disparities and other known predictive factors were independently associated with treatment performance and outcome. The inconsistent increase in treatment withdrawal in patients who started treatment later in the year could be explained by the gradual spread of concepts related to response-guided therapy [16], which is chiefly based on cost effectiveness, especially in treatment of hard-to-cure patients [17].

It should be emphasized that the rates of treatment accomplishment and SVR in the Hokkaido/Tohoku and Shikoku regions were significantly lower among 9 regions. A strong correlation between SVR rate and treatment 
Table 1 Demographic features of patients with chronic hepatitis C treated with interferon (IFN) in nine regions of Japan

\begin{tabular}{|c|c|c|c|c|c|c|c|c|c|c|c|}
\hline & All & Hokkaido/Tohoku & Kanto & Shin-etsu & Hokuriku & Tokai & Kinki & Chugoku & Shikoku & Kyushu & $P$-value \\
\hline$n$ & 16854 & 2055 & 1142 & 781 & 1046 & 1170 & 3565 & 2599 & 716 & 3780 & \\
\hline Age (years) ${ }^{a}$ & $57.9 \pm 10.9$ & $56.9 \pm 10.5$ & $56.5 \pm 11.3$ & $59.4 \pm 10.1$ & $60.2 \pm 9.3$ & $58.7 \pm 10.4$ & $57.3 \pm 11.6$ & $59.3 \pm 10.7$ & $57.8 \pm 10.1$ & $57.5 \pm 11.1$ & $<0.001^{b}$ \\
\hline $\begin{array}{l}\text { The elderly } \\
\text { ( } \geq 65 \text { years) (\%) }\end{array}$ & 30.2 & 26.1 & 24.9 & 34.4 & 35.3 & 32.5 & 29.9 & 34.9 & 26.7 & 28.7 & $<0.001^{c}$ \\
\hline $\begin{array}{l}\text { Gender } \\
\text { male (\%) }\end{array}$ & 50.4 & 50.6 & 53.3 & 46.7 & 44.3 & 48.8 & 51.5 & 49.7 & 54.6 & 51.2 & $<0.001^{c}$ \\
\hline $\begin{array}{l}\text { IFN-experienced } \\
\text { cases (\%) }\end{array}$ & 25.2 & 25.4 & 18.8 & 26.1 & 28.7 & 22.3 & 23.7 & 28.8 & 31.2 & 24.4 & $<0.001^{\mathrm{C}}$ \\
\hline $\begin{array}{l}\text { HCV Genotype } \\
1 / 2 / 3 / \\
\text { undetermined (\%) }\end{array}$ & $\begin{array}{l}\text { 63.5/34.7/ } \\
0.2 / 1.7\end{array}$ & $\begin{array}{l}64.2 / 32.8 / \\
0.0 / 2.9\end{array}$ & $\begin{array}{l}56.4 / 42.0 / \\
0.1 / 1.5\end{array}$ & $\begin{array}{l}68.5 / 29.4 / \\
0.0 / 2.1\end{array}$ & $\begin{array}{l}\text { 67.3/30.9/ } \\
0.0 / 1.8\end{array}$ & $\begin{array}{l}63.1 / 35.1 / \\
0.2 / 1.6\end{array}$ & $\begin{array}{l}65.0 / 32.1 / \\
0.4 / 2.5\end{array}$ & $\begin{array}{l}64.2 / 34.9 / \\
0.4 / 0.5\end{array}$ & $\begin{array}{l}56.7 / 41.9 / \\
0.1 / 1.3\end{array}$ & $\begin{array}{l}62.5 / 36.4 / \\
0.0 / 1.0\end{array}$ & $<0.001^{c}$ \\
\hline
\end{tabular}

${ }^{a}$ Age is shown as mean \pm standard deviation

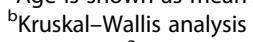

'Pearson's $X^{2}$ test

IFN, Interferon; $H C V$, Hepatitis $C$ virus 


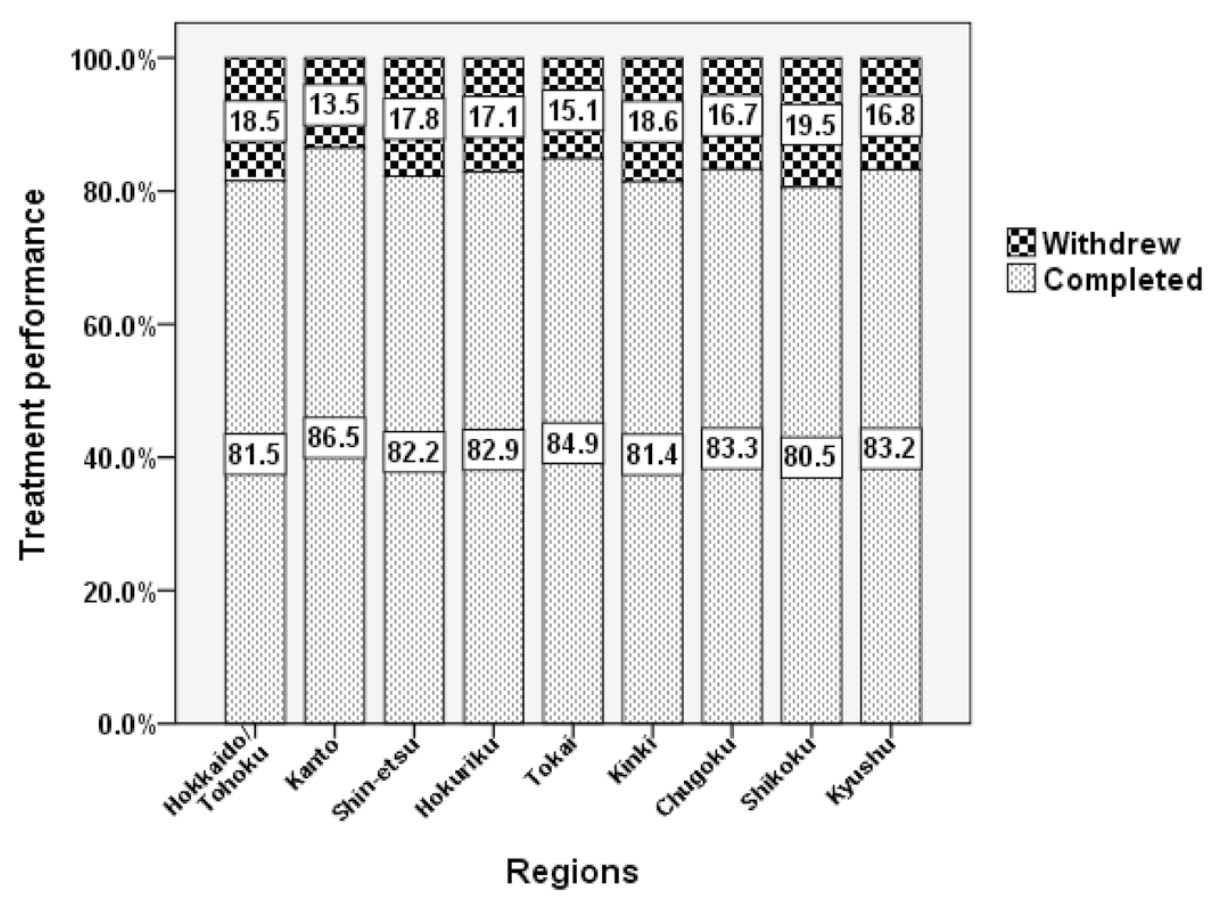

Fig. 2 Regional disparities in treatment performance in patients with chronic hepatitis $C$ treated by peginterferon- $a$ and ribavirin (P/R). As for the rates of treatment accomplishment, the average of the P/R-treated cohort was $82.8 \%$, and was higher than the average in five regions (Kanto, Hokuriku, Tokai, Chugoku, and Kyushu), and lower than average in the other four. The rates of treatment accomplishment differed significantly among the nine regions $(P=0.009)$

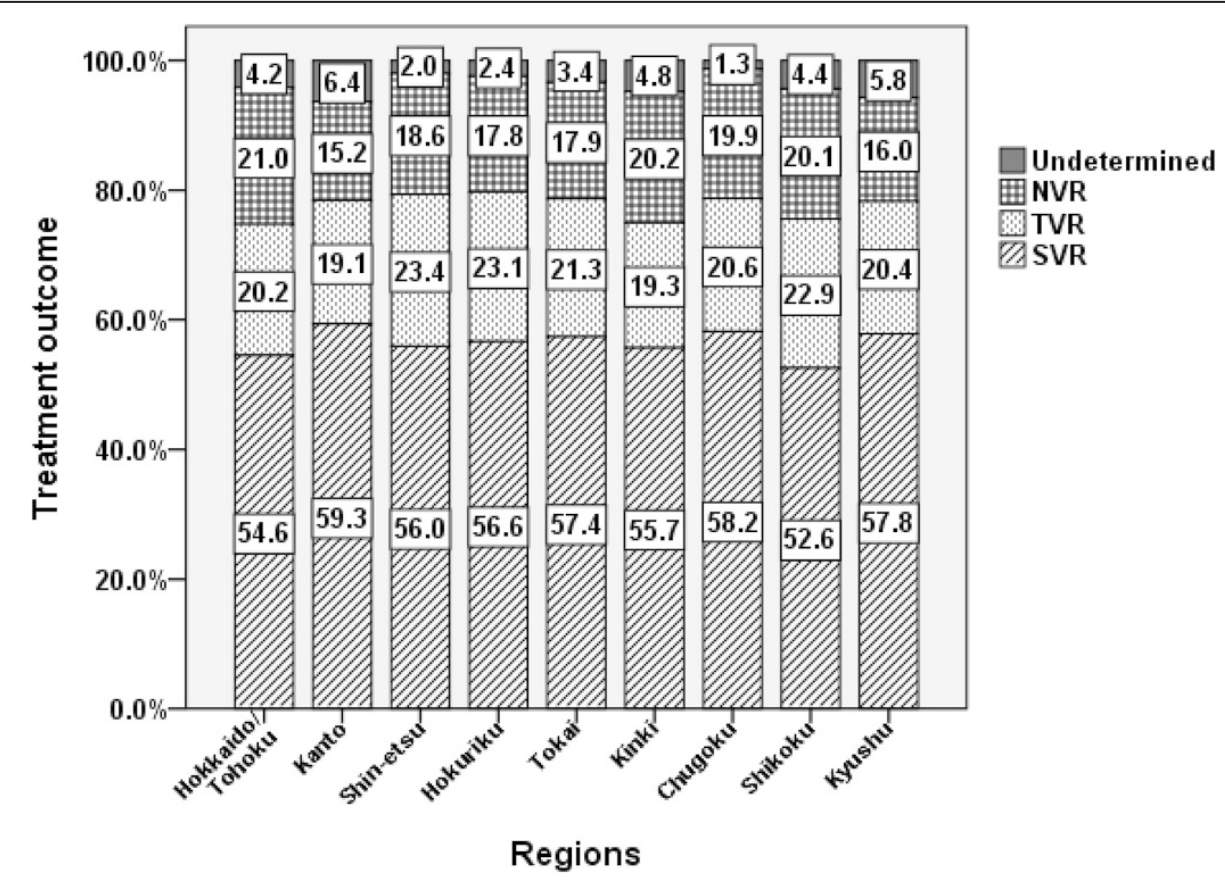

Fig. 3 Regional disparities in treatment outcome in patients with chronic hepatitis $C$ treated by peginterferon-a and ribavirin (P/R). In the entire P/R-treated cohort $(n=14,061)$, the treatment outcome was as follows: the rates of sustained virological response (SVR), transient virological response (TVR), non-virological response (NVR), and undetermined response were $56.7 \%, 20.6 \%, 18.6 \%$, and $4.1 \%$, respectively. There were regional disparities among the nine regions in treatment outcome $(P<0.001)$ 


\section{a) Treatment accomplishment/withdrawal}

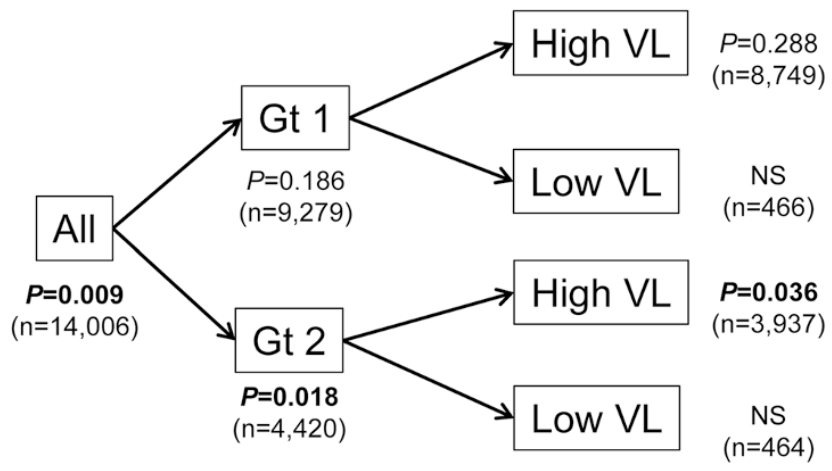

b) Treatment outcome

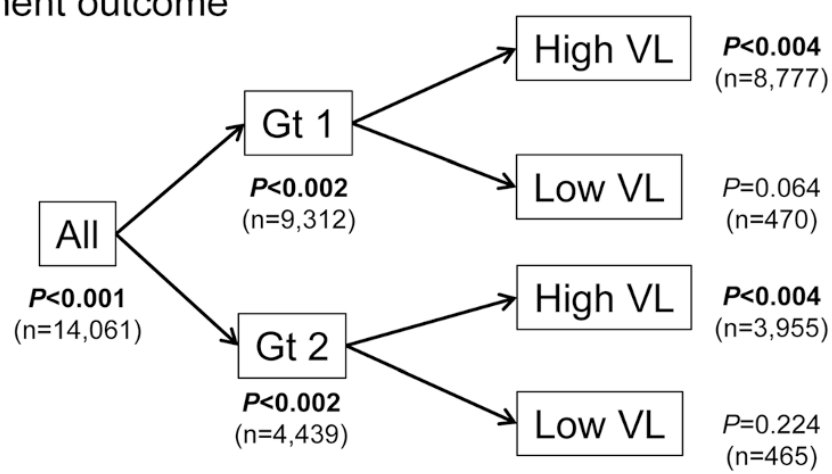

Fig. 4 Summary of regional disparities in treatment performance and outcome, in subgroups stratified with genotypes and viral loads of hepatitis $C$ virus (HCV). a Treatment performance. Regional disparities were detected in the genotype 2 subgroup $(P=0.018)$, especially with high viral load $(P=0.036)$, but not in genotype 1. b Treatment outcome. Regional disparities were confirmed in the subgroups with high viral load, regardless of HCV genotypes. The $P$-values were adjusted with the Bonferroni method for the number of strata

accomplishment rate $(r=0.879, P=0.002$; Additional file 1: Figure S1) suggests the presence of factors that influence treatment accomplishment, leading to non-SVR, in these two regions. Although the percentage of IFNexperienced cases in Shikoku was higher than in other regions, a history of IFN treatment was not chosen as a predictive factor for treatment accomplishment by multivariate analysis. The reasons for treatment withdrawal were divided into two categories: severe adverse events, and unrelated incidents. The proportions of these two categories were $\sim 60$ and $\sim 40 \%$, respectively, throughout Japan, and there was no regional difference among the nine regions (Additional file 2: Figure S2). However, in the category of unrelated incidents, the proportion with "poor response to $\mathrm{P} / \mathrm{R}$, according to criteria for response-guided therapy" differed among the nine regions $(P=0.019$; Additional file 3: Figure S3). In Hokkaido/Tohoku, the proportion was the lowest among the nine regions, which suggests the presence of the other factors peculiar to this region. Treatment accomplishment rate and SVR rate were not associated with the proportion of elderly patients in the P/R-treated cohort (Additional file 4: Figure S4 and Additional file 5: Figure S5) or the numbers of specialists in hepatology, designated by the Japan Society of Hepatology, per 100,000 people in each region (Additional file 6: Figure S6 and Additional file 7: Figure S7). Therefore, we need to consider another possibility such as limited accessibility to medical resources, particularly in the regions with low population density. Hokkaido and Tohoku are the regions with the lowest population density in Japan (Additional file 8: Figure S8). Therefore, consultation networks between base hospitals and local clinics should be constructed and properly managed by public health actions, especially in those regions.

Many findings similar to our study have recently been accumulated by public health policies regarding regional disparities in the treatment outcome of acute illness and malignant disorders. O'Connor et al. have reported that substantial geographic variation exists in the treatment of patients with acute myocardial infarction in the US, probably resulting from underuse of therapies with proven benefit in local clinical practices [18]. Gentry et al. recently proposed that geographic disparities in the 90-day transplant rates and waiting-list death rates for liver transplantation in the US could be reduced by redistricting based on 
Table 2 Factors associated with withdrawal of peginterferon-a and ribavirin treatment in chronic hepatitis C patients

\begin{tabular}{|c|c|c|c|c|c|c|c|c|}
\hline \multirow{2}{*}{\multicolumn{2}{|c|}{ Factors }} & \multicolumn{2}{|c|}{ Groups } & \multicolumn{2}{|c|}{ Univariate analysis } & \multicolumn{2}{|c|}{ Multivariate analysis } & \multirow[b]{2}{*}{95 \% C.I. } \\
\hline & & Treatment accomplishment & Treatment withdrawal & Coefficient & $P$-value & B & Odds ratio & \\
\hline \multicolumn{2}{|c|}{ Gender (Male/Female) } & $5824 / 5766$ & $1184 / 1226$ & 1.004 & 0.325 & 0.000 & 1.000 & $0.911-1.099$ \\
\hline \multicolumn{2}{|c|}{ Age ( $\geq 65$ years $/<65$ years) } & $3146 / 8423$ & $930 / 1473$ & 127.536 & $<0.001$ & -0.326 & 0.722 & $0.651-0.800$ \\
\hline \multicolumn{2}{|c|}{$\begin{array}{l}\text { History of IFN treatment } \\
\text { (naive/experienced) }\end{array}$} & $8463 / 2928$ & $1716 / 657$ & 4.005 & 0.047 & 0.032 & 1.033 & $0.929-1.147$ \\
\hline \multicolumn{2}{|l|}{ Genotype $(1 / 2+3)$} & $7326 / 4050$ & $1953 / 397$ & 311.818 & $<0.001$ & -1.007 & 0.365 & $0.324-0.412$ \\
\hline \multicolumn{2}{|c|}{ Viral load (high/low) } & $10713 / 817$ & $2248 / 141$ & 4.327 & 0.038 & -0.091 & 0.913 & $0.750-1.112$ \\
\hline \multicolumn{2}{|l|}{ Pre-AST $(U / L)^{a}$} & $43[30-68](n=11511)$ & 48 [34-73] $(n=2385)$ & & $<0.001$ & 0.001 & 1.001 & $1.000-1.003$ \\
\hline \multicolumn{2}{|l|}{ Pre-ALT $(U / L)^{a}$} & $51[31-87](n=11517)$ & $52[34-81](n=2384)$ & & 0.517 & & & \\
\hline \multirow{2}{*}{\multicolumn{2}{|c|}{ Pre-PLT (x104/ $/ \mu \mathrm{L})$}} & $16.0[13.0-20.0]$ & 15.0 [12.0-19.0] & & $<0.001$ & 0.001 & 1.001 & $0.990-1.013$ \\
\hline & & $(n=11381)$ & $(n=2349)$ & & & & & \\
\hline \multirow{2}{*}{\multicolumn{2}{|c|}{ FIB-4 index }} & $2.26[1.48-3.42]$ & $2.84[1.84-4.28]$ & & $<0.001$ & -0.125 & 0.882 & $0.850-0.916$ \\
\hline & & $(n=11349)$ & $(n=2341)$ & & & & & \\
\hline \multirow{3}{*}{$\begin{array}{l}\text { Year of starting } \\
\text { treatment }\end{array}$} & -2008 & 4624 & 804 & & & & Reference & \\
\hline & 2009 & 2845 & 588 & 45.561 & $<0.001$ & -0.219 & 0.803 & $0.710-0.909$ \\
\hline & 2010 & 4119 & 1015 & & & -0.496 & 0.609 & $0.545-0.680$ \\
\hline \multirow[t]{9}{*}{ Region } & Hokkaido/Tohoku & 1404 & 318 & & & -0.242 & 0.785 & $0.666-0.925$ \\
\hline & Kanto & 793 & 124 & & & 0.180 & 1.197 & $0.958-1.497$ \\
\hline & Shin-etsu & 528 & 114 & & & 0.020 & 1.020 & $0.802-1.297$ \\
\hline & Hokuriku & 717 & 148 & & & 0.036 & 1.037 & $0.838-1.283$ \\
\hline & Tokai & 814 & 145 & 20.418 & 0.009 & 0.231 & 1.260 & $1.019-1.558$ \\
\hline & Kinki & 2385 & 544 & & & -0.048 & 0.953 & $0.827-1.098$ \\
\hline & Chugoku & 1890 & 380 & & & 0.006 & 1.006 & $0.864-1.172$ \\
\hline & Shikoku & 476 & 115 & & & -0.240 & 0.787 & $0.619-0.999$ \\
\hline & Kyushu & 2589 & 522 & & & & Reference & \\
\hline
\end{tabular}

The values of pre-AST, pre-ALT, pre-PLT, and FIB-4 index are shown as median [interquartile range]

asince pre-AST and pre-ALT were closely correlated $(r=0.872 ; P<0.001)$, only pre-AST was included in multivariate analysis. Significant factors by multivariate analysis are shown in bold. The patients whose treatment performance could not be determined were excluded from this analysis $(n=55)$

$A L T$, Alanine aminotransferase; AST, Aspartate aminotransferase; C.I., Confidence interval; FIB-4, Fibrosis-4; IFN, Interferon; PLT, Platelets; SVR, Sustained virological response

optimal liver allocation [19]. Brantley-Sieders et al. also found that breast cancer mortality rates, which varied among counties in Middle Tennessee, correlated with additional risk factors (i.e., mammography screening and socioeconomic status) and proposed resources to reduce breast cancer mortality [20]. In contrast, information regarding regional disparities for the treatment of $\mathrm{CHC}$ with $\mathrm{P} / \mathrm{R}$ is limited. In the IDEAL Study, no significant differences were detected in the various metrics of quality and site performance (i.e., adherence, adverse events, treatment withdrawal, on-treatment virological response, and SVR) between 76 academic-based and 42 communitybased centers in the US [21]. Based on these previous studies, further evaluations of local clinical practices should be mandatory to explore the reasons for regional disparities in treatment and outcome of $\mathrm{P} / \mathrm{R}$ therapy in Japan, especially in the two regions identified in our study, Hokkaido/Tohoku and Shikoku. Again, access to medical treatment would be a serious burden on patients who are company employees or residents in the regions with low population density, partly because the self-injection of peginterferon- $\alpha$ has not yet been approved by the Pharmaceutical Affairs Law in Japan.

Owing to the introductions of IFN-free regimens of DAAs, use of IFN is limited to settings in which new treatments may initially be too expensive to be utilized [22]. Considering that $\mathrm{HCV}$ infection may cause chronic and morbid liver diseases (i.e., liver cirrhosis or hepatocellular carcinoma), such a perspective is acceptable in general. However, at the same time, we should pay close attention to the presence or emergence of resistance to those DAAs. In particular, with the recently approved simeprevir, up to $40 \%$ of patients in the US infected with genotype $1 \mathrm{a} \mathrm{HCV}$ have Q80K mutation before treatment. Thus, it is strongly recommended this polymorphism should be screened prior to treatment with 
Table 3 Factors associated with non-sustained virological response to peginterferon-a and ribavirin treatment in chronic hepatitis C patients

\begin{tabular}{|c|c|c|c|c|c|c|c|c|}
\hline \multirow{2}{*}{ Factors } & & \multicolumn{2}{|l|}{ Groups } & \multicolumn{2}{|c|}{ Univariate analysis } & \multicolumn{2}{|c|}{ Multivariate analysis } & \multirow[b]{2}{*}{$95 \%$ C.I. } \\
\hline & & SVR & Non-SVR & Coefficient & $P$-value & B & Odds ratio & \\
\hline \multicolumn{2}{|l|}{ Gender (Male/Female) } & $4234 / 3740$ & $2426 / 3080$ & 106.402 & $<0.001$ & -0.302 & 0.739 & $0.683-0.800$ \\
\hline \multicolumn{2}{|l|}{ Age ( $\geq 65$ years $/<65$ years) } & $1865 / 6093$ & $2079 / 3414$ & 325.742 & $<0.001$ & -0.392 & 0.676 & $0.618-0.739$ \\
\hline \multicolumn{2}{|l|}{$\begin{array}{l}\text { History of IFN treatment } \\
\text { (naïve/experienced) }\end{array}$} & $6106 / 1733$ & $3676 / 1755$ & 172.508 & $<0.001$ & -0.407 & 0.665 & $0.610-0.726$ \\
\hline \multicolumn{2}{|l|}{ Genotype $(1 / 2+3)$} & $4386 / 3439$ & $4577 / 818$ & 1212.744 & $<0.001$ & -1.344 & 0.261 & $0.238-0.286$ \\
\hline \multicolumn{2}{|l|}{ Viral load (high/low) } & $7204 / 736$ & $5281 / 182$ & 178.857 & $<0.001$ & -1.213 & 0.297 & $0.247-0.359$ \\
\hline \multicolumn{2}{|l|}{ Pre-AST $(U / L)^{*}$} & $43[30-69](n=7928)$ & $45[32-68](n=5457)$ & & $<0.001$ & & & \\
\hline \multicolumn{2}{|l|}{ Pre-ALT $(U / L)^{*}$} & $54[31-93](n=7931)$ & $48[31-75](n=5459)$ & & $<0.001$ & 0.005 & 1.005 & $1.004-1.005$ \\
\hline \multicolumn{2}{|l|}{ 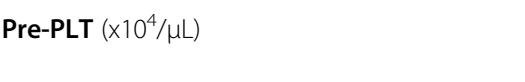 } & $\begin{array}{l}17.0[14.0-21.0] \\
(n=7855)\end{array}$ & $\begin{array}{l}15.0[12.0-19.0] \\
(n=5374)\end{array}$ & & $<0.001$ & 0.018 & 1.019 & $1.009-1.029$ \\
\hline \multicolumn{2}{|l|}{ FIB-4 index } & $\begin{array}{l}2.11[1.36-3.20] \\
(n=7833)\end{array}$ & $\begin{array}{l}2.77[1.86-4.15] \\
(n=5357)\end{array}$ & & $<0.001$ & -0.164 & 0.849 & $0.821-0.877$ \\
\hline \multirow[t]{3}{*}{ Year of starting treatment } & -2008 & 3062 & 2327 & & & & Reference & \\
\hline & 2009 & 1958 & 1362 & 7.949 & 0.019 & -0.085 & 0.918 & $0.831-1.015$ \\
\hline & $2010-$ & 2950 & 1915 & & & -0.095 & 0.909 & $0.830-0.997$ \\
\hline \multirow[t]{9}{*}{ Region } & Hokkaido/Tohoku & 941 & 711 & & & -0.288 & 0.750 & $0.653-0.861$ \\
\hline & Kanto & 547 & 316 & & & -0.064 & 0.938 & $0.786-1.119$ \\
\hline & Shin-etsu & 361 & 271 & & & -0.069 & 0.933 & $0.765-1.137$ \\
\hline & Hokuriku & 490 & 354 & & & -0.032 & 0.969 & $0.815-1.152$ \\
\hline & Tokai & 557 & 381 & 21.777 & 0.005 & -0.069 & 0.934 & $0.789-1.105$ \\
\hline & Kinki & 1637 & 1160 & & & -0.116 & 0.891 & $0.790-1.004$ \\
\hline & Chugoku & 1322 & 920 & & & -0.044 & 0.957 & $0.844-1.085$ \\
\hline & Shikoku & 314 & 257 & & & -0.399 & 0.671 & $0.546-0.825$ \\
\hline & Kyushu & 1808 & 1138 & & & & Reference & \\
\hline
\end{tabular}

The values of pre-AST, pre-ALT, pre-PLT, and FIB-4 index are shown as median [interquartile range]

${ }^{a}$ Since pre-AST and pre-ALT were closely correlated $(r=0.872 ; P<0.001)$, only pre-ALT was included in multivariate analysis. Significant factors by multivariate analysis are shown in bold. The patients whose treatment outcome could not be determined were excluded from this analysis $(\mathrm{n}=576$ )

$A L T$, Alanine aminotransferase; AST, Aspartate aminotransferase; C.I., Confidence interval; FIB-4, Fibrosis-4; IFN, Interferon; PLT, Platelets; SVR, Sustained virological response

P/R plus simeprevir, according to the American Association for the Study of Liver Diseases/Infectious Diseases Society of America Recommendations [23]. In addition, we need to think about the possibility of unexpected emergence of resistance to various forthcoming DAAs, in case of patients with poor drug adherence or viral breakthrough. The necessity for adequate education of general physicians, as well as HCV-infected patients, should be emphasized, for standardized performance and outcome of the forthcoming treatment, including DAAs.

There were several limitations to this study. First, our nationwide database consisted of only $\sim 20 \%$ of patients in the prefectures who benefited from the governmental subsidy policy, and was not reflective of all patients in Japan. However, considering that the difference in the percentage of elderly patients ( $\geq 65$ years) between our collected reports and all applicants for this subsidy during the initial 3 years in each prefecture was only $1.3 \%$ (median; interquartile range:-2.7 to $4.1 \%$; preliminary analysis for 26 prefectures), we may assume that our database represents all the patients who benefited from this subsidy policy. Second, the number of collected parameters was inevitably influenced by the willingness of the doctors to complete the reports during daily clinical practice. Thereby, information regarding the doctors' specialty, drug adherence, or treatment outcome of previously administered IFN could not be included in this analysis. Third, generalizability of our findings is necessary, however, it is difficult for this type of large cohort study for $\mathrm{P} / \mathrm{R}$ therapy in a rapidly changing era of treatment modalities for $\mathrm{CHC}$. Finally, we were unable to collect information regarding the accessibility to medical resources for individual patients, which may have affected treatment accomplishment. Further investigation would be indispensable to evaluate this issue, by analyzing additional factors in those areas, such as a going-to- 
hospital time, availability of consultation networks between base hospitals and local clinics, and so on.

\section{Conclusions}

Treatment performance and outcome in patients with $\mathrm{CHC}$ are not yet standardized in Japan and further investigations to solve the problems of regional disparities should be performed from the viewpoint of local clinical practice. The policies for treatment of hepatitis by the Japanese government should be formulated to correspond with the characteristics of the respective jurisdictions so that the patients with viral hepatitis may receive the highest standard of medical care, regardless of the locality where they reside.

\section{Additional files}

Additional file 1: Figure S1. Correlation between treatment accomplishment and sustained virological response (SVR) rates in patients treated by peginterferon-a and ribavirin in nine regions of Japan. SVR rates were strongly correlated with the rates of treatment accomplishment $(r=0.879, P=0.002)$.

Additional file 2: Figure S2. Rates of severe adverse events (SAE) and unrelated incidents among the reasons for withdrawal of peginterferon- $a$ and ribavirin therapy. There was no regional difference among nine regions of Japan $(P=0.075)$.

Additional file 3: Figure S3. Rates of poor response to peginterferon- $a$ and ribavirin $(P / R)$ and other agents as reasons for treatment withdrawal because of unrelated incidents. The proportion of patients with poor response to $P / R$, according to criteria for response-guided therapy differed among nine regions of Japan $(P=0.019)$. In Hokkaido/Tohoku the proportion was the lowest.

Additional file 4: Figure S4. Proportions of elderly patients and treatment accomplishment rate for peginterferon- $a$ and ribavirin in nine regions of Japan. No correlation was found between the proportions of elderly patients and treatment accomplishment rate $(r=-0.107, P=0.783)$.

Additional file 5: Figure S5. Proportions of elderly patients and sustained virological response (SVR) rate in patients treated by peginterferon- $a$ and ribavirin in nine regions of Japan. No correlation was found between the proportions of elderly patients and SVR rate ( $r=0.133, P=0.733)$.

Additional file 6: Figure S6. Numbers of specialists in hepatology and treatment accomplishment rate in patients treated by peginterferon- $a$ and ribavirin in nine regions of Japan. No correlation was found between these two parameters $(r=0.030, P=0.939)$.

Additional file 7: Figure S7. Numbers of specialists in hepatology and sustained virological response (SVR) rate in patients treated by peginterferon- $a$ and ribavirin in nine regions of Japan. No correlation was found between these two parameters $(r=0.088, P=0.822)$.

Additional file 8: Figure S8. Population density in each region in Japan. The figures were calculated based on the Basic Resident Register of Japan in 2013 (http://www.soumu.go.jp/menu_news/s-news/ 01gyosei02_02000055.html). In this figure, data for the Hokkaido and Tohoku regions are shown separately.

\section{Abbreviations}

ALT: Alanine aminotransferase; AST: Aspartate aminotransferase; CHC: Chronic hepatitis C; Cl: Confidence interval; DAAs: Directly acting antivirals; FIB-4: Fibrosis-4; HBV: Hepatitis B virus; HCV: Hepatitis C virus; IFN: Interferon; NVR: Nonvirological response; PLT: Platelets; P/R: Peginterferon-a and ribavirin; SVR: Sustained virological response; TVR: Transient virological response.

\section{Competing interests}

The authors declare that they have no competing interests.

\section{Authors' contributions}

NM was responsible for the study concept and design, obtaining funding, analyzing and interpreting data, and drafting the manuscript. YY and TS were responsible for the analysis and interpretation of data, and critical review of the manuscript for important intellectual content. Data was acquired by NM, YY, KM, MK and TK. This study was conducted under the supervision of MM. All authors read and approved the final manuscript.

\section{Acknowledgments}

Financial support was provided by the Grant-in-Aid from the Ministry of Health, Labour and Welfare, Japan (Research on Hepatitis: 2009-2014) to NM. The funding source had no involvement in the study design, data collection, analysis, and interpretation, writing of this manuscript, or decision to submit this manuscript for publication. The authors thank Ms. Mikako Kajio and Ms. Asako Horihata for technical assistance during data analysis. The great contributions of the 37 prefectural members and all the medical staffs engaged in the long-term interferon treatment and data collection are particularly acknowledged.

\section{Author details}

${ }^{1}$ The Research Center for Hepatitis and Immunology, National Center for Global Health and Medicine, 1-7-1 Kohnodai, Ichikawa, Chiba 272-8516, Japan. ${ }^{2}$ Department of Clinical Study and Informatics, Center for Clinical Sciences, National Center for Global Health and Medicine, Tokyo 162-8655, Japan.

Received: 13 August 2014 Accepted: 29 May 2015

Published online: 19 June 2015

\section{References}

1. WHO Fact sheet $N^{\circ} 164$, Updated April 2014. Hepatitis C. [http://www.who.int/ mediaCenter/factsheets/fs164/en/index.html] (Accessed June 1, 2015)

2. Ghany MG, Nelson DR, Strader DB, Thomas DL, Seeff LB. An update on treatment of genotype 1 chronic hepatitis C virus infection: 2011 Practice guideline by the American Association for the Study of Liver Diseases. Hepatology. 2011;54:1433-43.

3. Poordad F, McCone Jr J, Bacon BR, Bruno S, Manns MP, Sulkowski MS, et al Boceprevir for untreated chronic HCV genotype 1 infection. N Engl J Med. 2011;364:1195-206.

4. Bacon BR, Gordon SC, Lawitz E, Marcellin P, Vierling JM, Zeuzem S, et al. Boceprevir for previously treated chronic HCV genotype 1 infection. N Engl J Med. 2011;364:1207-17.

5. Jacobson IM, McHutchison JG, Dusheiko G, Di Bisceglie AM, Reddy KR, Bzowej $\mathrm{NH}$, et al. Telaprevir for previously untreated chronic hepatitis $\mathrm{C}$ virus infection. N Engl J Med. 2011;364:2405-16.

6. McHutchison JG, Manns MP, Muir AJ, Terrault NA, Jacobson IM, Afdhal NH, et al. Telaprevir for previously treated chronic HCV infection. N Engl J Med. 2010;362:1292-303.

7. Hayashi N, Izumi N, Kumada H, Okanoue T, Tsubouchi H, Yatsuhashi H, et al. Simeprevir with peginterferon/ribavirin for treatment-naïve hepatitis $C$ genotype 1 patients in Japan: CONCERTO-1, a phase III trial. J Hepatol. 2014;61:219-27.

8. Jacobson IM, Dore GJ, Foster GR, Fried MW, Radu M, Rafalsky W, et al. Simeprevir with pegylated interferon alfa 2a plus ribavirin in treatment-naive patients with chronic hepatitis C virus genotype 1 infection (QUEST-1): a phase 3, randomised, double-blind, placebo-controlled trial. Lancet. 2014;384:403-13.

9. Gane EJ, Stedman CA, Hyland RH, Ding X, Svarovskaia E, Symonds WT, et al. Nucleotide polymerase inhibitor sofosbuvir plus ribavirin for hepatitis $C$. N Engl J Med. 2013;368:34-44.

10. Lawitz E, Poordad FF, Pang PS, Hyland RH, Ding X, Mo H, et al. Sofosbuvir and ledipasvir fixed-dose combination with and without ribavirin in treatment-naive and previously treated patients with genotype 1 hepatitis C virus infection (LONESTAR): an open-label, randomised, phase 2 trial. Lancet. 2014:383:515-23.

11. Kumada H, Suzuki Y, Ikeda K, Toyota J, Karino Y, Chayama K, et al. Daclatasvir plus asunaprevir for chronic HCV genotype 1b infection. Hepatology. 2014;59:2083-91. 
12. Japanese Law Translation. Basic Act on Hepatitis Measures. [http:// www.japaneselawtranslation.go.jp/law/detail/?id=1995\&vm=04\&re=01] (Accessed June 1, 2015)

13. Ghany MG, Strader DB, Thomas DL, Seeff LB, American Association for the Study of liver Diseases. Diagnosis, management, and treatment of hepatitis C: an update. Hepatology. 2009;49:1335-74.

14. Izumi N, Nishiguchi S, Hino K, Suzuki F, Kumada H, Itoh $Y$, et al. Management of hepatitis C; Report of the Consensus Meeting at the 45th Annual Meeting of the Japan Society of Hepatology (2009). Hepatol Res. 2010;40:347-68.

15. Sterling RK, Lissen E, Clumeck N, Sola R, Correa MC, Montaner J, et al. Development of a simple noninvasive index to predict significant fibrosis in patients with HIV/HCV coinfection. Hepatology. 2006:43:1317-25.

16. Wedemeyer H, Jensen DM, Godofsky E, Mani N, Pawlotsky JM, Miller V, et al. Recommendations for standardized nomenclature and definitions of viral response in trials of hepatitis $C$ virus investigational agents. Hepatology. 2012:56:2398-403.

17. McEwan P, Kim R, Yuan Y. Assessing the cost utility of response-guided therapy in patients with chronic hepatitis $C$ genotype 1 in the UK using the MONARCH model. Appl Health Econ Health Policy. 2013;11:53-63.

18. O'Connor GT, Quinton HB, Traven ND, Ramunno LD, Dodds TA, Marciniak TA, et al. Geographic variation in the treatment of acute myocardial infarction: the cooperative cardiovascular project. JAMA. 1999;281:627-33.

19. Gentry SE, Massie AB, Cheek SW, Lentine KL, Chow EH, Wickliffe CE, et al. Addressing geographic disparities in liver transplantation through redistricting. Am J Transplant. 2013;13:2052-8.

20. Brantley-Sieders DM, Fan K-H, Deming-Halverson SL, Shyr Y, Cook RS, Local breast cancer spatial patterning. A tool for community health resource allocation to address local disparities in breast cancer mortality. PLoS One. 2012;7, e45238.

21. Jou JH, Sulkowski MS, Noviello S, Long J, Pedicone LD, McHutchison JG, et al. Analysis of site performance in academic-based and community-based centers in the IDEAL Study. J Clin Gastroenterol. 2013:47:e91-5.

22. Thomas DL. Cure of hepatitis C virus infection without interferon alfa: scientific basis and current clinical evidence. Top Antivir Med. 2014:21:152-6.

23. AASLD-IDSA Recommendations for Testing, Managing and Treating Hepatitis C: Initial treatment of HCV infection. [http://www.hcvguidelines.org/full-report/ initial-treatment-hcv-infection] (Accessed June 1, 2015)

\section{Submit your next manuscript to BioMed Central and take full advantage of:}

- Convenient online submission

- Thorough peer review

- No space constraints or color figure charges

- Immediate publication on acceptance

- Inclusion in PubMed, CAS, Scopus and Google Scholar

- Research which is freely available for redistribution 